\title{
Two Designs of Thin Film for Cooling Buildings based on Photonic Crystal
}

\author{
Zhiyuan $\mathrm{Li}^{1}$, Zidong Qin ${ }^{1}$, Lun Tan ${ }^{2}$ \\ ${ }^{1}$ College of Civil Engineering, Tongji University, Shanghai, 200092, China \\ ${ }^{2}$ College of Physics, Tongji University, Shanghai, 200092, China
}

\begin{abstract}
Nowadays, air conditioning, a relatively energy-intensive method, is still the main way to cooling buildings. This paper proposes two designs of thin film which uses photonic crystal and is based on theories of black-body radiation and electrodynamics. By different designs, the two thin films have disparate photonic band gap, making them respectively suitable for wall and windows. As a new type of material for buildings, it has distinguished advantages of low-energy consumption and high efficiency.
\end{abstract}

Keywords-cooling photonic crystal; thin film; low-energy consumption

\section{PREFACE}

Technology for cooling buildings can be divided into active cooling and positive cooling. The main method in active cooling is by air conditioner, which is rather energy-inefficient. In China, the energy for using air conditioners accounts for nearly $60 \%$ consumption in buildings. Passive cooling, a method with low-energy consumption, refers to using natural conditions for cooling. There are many ways in passive cooling such as radiative cooling, evaporative cooling and reducing-heat-gain technology. However, cooling methods above rely so much on natural conditions that it is difficult for them to be applied in a massive scale.

A new research about one-dimensional photonic crystal published on Nature (Nov.27, 2014) attracts a great deal of attention. The authors, Professor AaswathP.Raman and his workmates, figure out a design of thin film based on photonic crystal, which can reflect $97 \%$ of sunlight and decrease on surface compared with normal glass of the same size. Since Yablonovitch and John firstly proposed the concept of photonic crystal in 1987, this material is intensively applied in optical communication, optoelectronic devices and elementary devices in integrated optics. The research greatly widens the application of photonic crystal and proposes a new low-consumptive cooling method for buildings.

However, there are many kinds of expensive metal in the design and the composition of the material is some complex. What's more, some layers are too thin to be produced. Hence, to achieve better cooling effect with cheaper material and fewer kinds of elements, combined with mathematical analysis of transmission matrix, this paper elaborates the train of design and proposes two designs respectively suitable for wall and windows in buildings. At the end of this paper, we present some ideas about further improvement of the cooling material, ideas about the thin film for heating buildings and the thin film with effect of cooling buildings in summer while heating in winter.

\section{INTRODUCTION OF DESIGN}

The core thought is to reflect outdoor sunlight in the maximal scale and prevent transmission of indoor thermal radiation as much as possible. The detailed introduction is as follows.

\section{A. Using theory of black-body radiation}

According to theory of black-body radiation, objects with higher temperature will emit electromagnetic wave with higher frequency and shorter wave length. Therefore, electromagnetic wave from the sun has much shorter wave length than that from objects in buildings. Next, according to statistics, about $50 \%$ energy of sunlight lies in the section of visible light $(0.400-0.760 \mu \mathrm{m}), 43 \%$ in infrared light $(0.760-1000 \mu \mathrm{m})$ and mostly in the wave length between $0.760 \mu \mathrm{m}$ and $1.200 \mu \mathrm{m}$. Then, according to other statistics, indoor objects and buildings radiate heat by specific infrared light $(6 \mu \mathrm{m}-30 \mu \mathrm{m})$ and some period of it $(8 \mu \mathrm{m}-13 \mu \mathrm{m})$ is severely hard to be absorbed by airborne molecular, eventually flying to distant atmosphere. Hence, if we cut off the transmission of major energy in sunlight $(0.400-1.200 \mu \mathrm{m})$ and ensure the transmission of main energy in buildings $(8 \mu \mathrm{m}-13 \mu \mathrm{m})$, the material will have a bilateral and efficient impact on cooling buildings.

\section{B. Design for structures and parameters}

Existing researches show that the more loops the structure of photonic crystal has and the greater the difference in refractive index between two materials is, the more easily photonic band gap will form. Also, the greater the distance in thickness of two layers is, the more distinct the position of two photonic band gaps will be. With the information above, we can reduce considerable data groups when simulating by computer.

\section{Respective designs for different usages}

When applied in wall, natural lighting needn't be considered because it is solid and opaque. So we try to make photonic band gap cover the range of visible light $(0.400-0.760 \mu \mathrm{m})$ and specific period of infrared light $(0.760 \mu \mathrm{m}-1.200 \mu \mathrm{m})$ while ensure high transmittance of electromagnetic wave from $8 \mu \mathrm{m}$ to $13 \mu \mathrm{m}$. When applied in windows, natural lighting ought to be carefully considered. So we try to make photonic band gap cover the part of infrared light $(0.760 \mu \mathrm{m}-1.200 \mu \mathrm{m})$ while ensure high transmittance of visible light $(0.400-0.760 \mu \mathrm{m})$ and electromagnetic wave from $8 \mu \mathrm{m}$ to $13 \mu \mathrm{m}$. 


\section{THEORETICAL ANALYSIS}

\section{A. Calculating field strength by transmission matrix}

Taking TE wave for example, the calculation on filed strength within one-dimensional photonic crystal is as follows.

In figure 1, two layers are ranged in periodic repeated array with thickness of $h_{1}$ and $h_{2}$, refractive index of $n_{1}$ and $\mathrm{n}_{2}$. The thickness of a loop is a and the number of loops is $\mathrm{N}$.

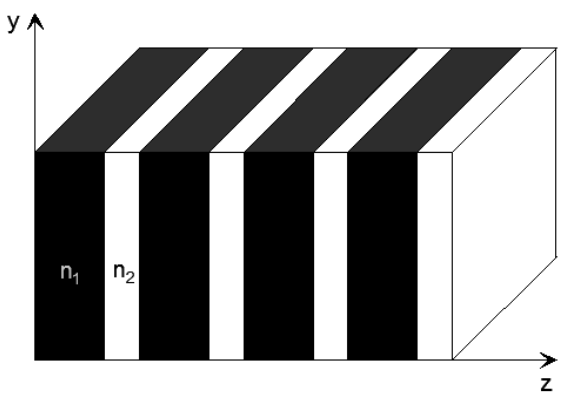

Figure 1. Arrangement graph of one-dimensional photonic crystal as:

In layer $\alpha(\alpha=1,2)$, the filed strength can be expressed

$$
\begin{aligned}
& E^{a}(y, z, t)=\left(A_{m}^{a} e^{i k \frac{\alpha}{z} \tilde{z}}+B_{m}^{a} e^{-i k \frac{\alpha}{z} \tilde{z}}\right) e^{i\left(k_{y}-w t\right)} \\
& 0 \leq \tilde{z} \leq a, z=\tilde{z}+m a, A_{m}^{a} \text { and } B_{m}^{a} \text { are the }
\end{aligned}
$$

amplitude of incident wave and reflected wave in loop $\mathrm{m}$, layer $\alpha$.

From layer 1 to layer 2 in cycle $m$, the tangent vector of electric field continues:

$$
E^{1}\left(y, h_{1}+m a, t\right)=E^{2}(y, h 1+m a, t)
$$

Also, the tangent vector of magnetic field continues:

$$
H_{t}^{1}\left(y, h_{1}+m a, t\right)=H_{t}^{2}\left(y, h_{1}+m a, t\right)
$$

The two equations can be written as:

$$
\begin{aligned}
& A_{m}^{1} e^{i k \frac{1}{z} h_{1}}+B{ }_{m}^{1} e^{-i k \frac{1}{z} h_{1}}=A_{m}^{2} e^{i k \frac{2}{z} h_{1}}+B{ }_{m}^{2} e^{-i k \frac{2}{z} h_{1}} \\
& k \frac{1}{Z}\left(A e^{1} e^{i k \frac{1}{z} h_{1}}-B{ }_{m}^{1} e^{-i k \frac{1}{z} h_{1}}\right)=k \frac{2}{z}\left(A{ }_{m}^{2} e^{i k \frac{2}{z} h_{1}}-B{ }^{2} e^{-i k \frac{2}{z} h_{1}}\right)
\end{aligned}
$$

In the form of matrix:

$$
\left(\begin{array}{cc}
e^{i k \frac{1}{2} h_{1}} & e^{-i k \frac{1}{2} h_{1}} \\
k \frac{1}{z} e^{i k \frac{1}{2} h_{1}} & -k \frac{1}{z} e^{-i k \frac{1}{2} h_{1}}
\end{array}\right)\left(\begin{array}{c}
A \\
m \\
B \\
B
\end{array}\right)=\left(\begin{array}{cc}
e^{i k \frac{2}{2} h_{1}} & e^{-i k \frac{1}{2} h_{1}} \\
k \frac{2}{z} e^{i k \frac{2}{2} h_{1}} & -k \frac{2}{z} e^{-i k \frac{2}{2} h_{1}}
\end{array}\right)\left(\begin{array}{c}
A \\
m \\
2 \\
B \\
m
\end{array}\right)
$$

Referring to the process above, from layer 2 in loop $\mathrm{m}$ to layer 1 in loop $\mathrm{m}+1$, we can get another matrix:

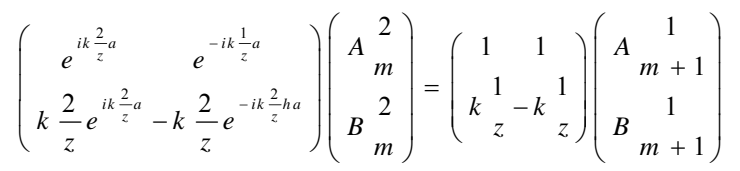
W:

For simplified expression, we introduce matrix $\mathrm{M}$ and

$$
M(k, z)=\left(\begin{array}{cc}
e^{i k z} & e^{-i k z} \\
k e^{i k z} & -k e^{i k z}
\end{array}\right) W \begin{aligned}
& a \\
& m
\end{aligned}=\left(\begin{array}{c}
A \\
m \\
B \\
m
\end{array}\right)
$$

Hence, (1) and (2) can be expressed as:

$$
\begin{aligned}
& M \underset{m}{1}\left(k \frac{1}{z}, h_{1}\right) W_{m}^{1}=M\left(k \frac{2}{z}, h_{1}\right) W_{m}^{2} \\
& M\left(k \frac{2}{z}, a\right) W_{m}^{2}=M\left(k \frac{1}{z}, 0\right) W_{m+1}^{1}
\end{aligned}
$$

Eventually, we find out the relationship from the formal loop to the latter one:

$$
W_{m+1}^{1}=M^{-1}\left(k \frac{1}{z}, 0\right) M\left(k \frac{2}{z}, a\right) M^{-1}\left(k \frac{2}{z}, h_{1}\right) M\left(k \frac{1}{z}, a\right) W_{m}^{1}
$$

B. Calculating transmittance and thickness

Defining matrix $\mathrm{T}$, $T=M^{-1}\left(k \frac{1}{z}, 0\right) M\left(k \frac{2}{z}, a\right) M^{-1}\left(k \frac{2}{z}, h_{1}\right) M\left(k \frac{1}{z}, h_{1}\right)$, we can get:

$$
W \underset{m+1}{1}=T W \underset{m}{1}
$$

By multiplying T, we get $\mathrm{L}$. For the last layer, there is no reflected wave, , then we get:

$$
\left.L W W_{1}^{1}=L\left(\begin{array}{ll}
A & 1 \\
1 \\
B & 1 \\
1
\end{array}\right)=W \quad \begin{array}{c}
1 \\
N+1
\end{array}\right)=\left(\begin{array}{c}
A \\
N+1 \\
0
\end{array}\right)
$$

Now, we can calculate field strength within one-dimensional photonic crystal after working out $\mathrm{L}$ and M. Here, we define transmittance:

$$
t=\left(\frac{A \begin{array}{c}
1 \\
N+1
\end{array}}{A \frac{1}{1}}\right)^{2}
$$

The optical path of each layer is $1 / 4$ wave length, after ensuring refractive index, the thickness can be calculated as:

$$
h_{1}=\frac{1 / 4 \lambda_{0}}{n_{1}} \quad h_{2}=\frac{1 / 4 \lambda_{0}}{n_{2}}
$$




\section{SIMULATING BY COMPUTER}

Using the software of Matlab, we build the modeling as figure 2 .

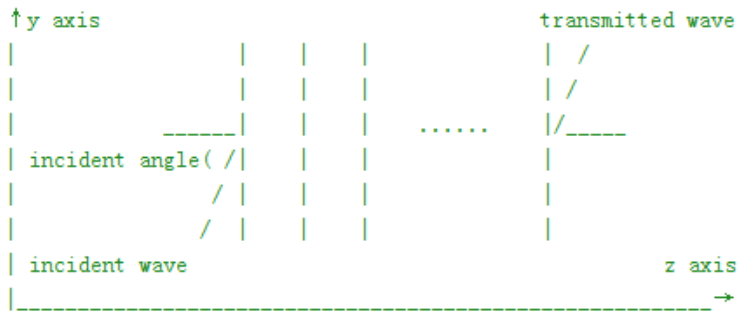

Figure 2. Primary modeling in Matlab

The main program consists of setting of constants, setting of structure of layers, setting of parameters and calculation on transmission matrix and transmittance. The program output a picture using wave length $(\mu \mathrm{m})$ as $\mathrm{x}$ axis and transmittance as y axis.

The subroutine program uses loop structure, aiming at searching for ideal material, thickness and structure. We save data of those designs which decrease transmittance to less than 0.1 from $0.4 \mu \mathrm{m}$ to $1.2 \mu \mathrm{m}$ and ensure transmittance more than 0.6 from $8.0 \mu \mathrm{m}$ to $13.0 \mu \mathrm{m}$ for further comparison and contrast.

\section{RESULTS}

\section{A. Design for wall}

Taking distinguished refractive index, production technique and production cost into account, we choose $\mathrm{SiO}_{2}$ as the first layer (transmittance: 1.45) and $\mathrm{TiO}_{2}$ (transmittance: 2.65)as the second layer. The structure is, as is shown in figure 3. Layer A,C,E,G correspond to $\mathrm{SiO}_{2}$ while layer $\mathrm{B}, \mathrm{D}, \mathrm{F}, \mathrm{H}$ correspond to $\mathrm{TiO}_{2}$. To decrease transmittance of visible light (the most energy-intensive section in sunlight) as much as possible, the center positions of photonic band gap of layer A,B,C,D are set to $0.35 \mu \mathrm{m}, 0.40 \mu \mathrm{m}, 0.45 \mu \mathrm{m}, 0.50 \mu \mathrm{m}$. To widen the range of photonic band gap, the center positions of photonic band gap of layer E,F,G,H are set to $0.60 \mu \mathrm{m}, 0.75 \mu \mathrm{m}, 0.90 \mu \mathrm{m}, 1.05 \mu \mathrm{m}$. Calculated by formulas above, The thickness of layer A,B,C,D,E,F,G,H are $60 \mathrm{~nm}$, $38 \mathrm{~nm}, 78 \mathrm{~nm}, 47 \mathrm{~nm}, 103 \mathrm{~nm}, 71 \mathrm{~nm}, 155 \mathrm{~nm}, 99 \mathrm{~nm}$. The results are shown in figure 4 and figure 5 . It is obvious that transmittance of visible light $(0.40 \mu \mathrm{m}-0.76 \mu \mathrm{m})$ is approximately below 0.01 with the peak below 0.02 , and transmittance of specific period of infrared light $(0.76 \mu \mathrm{m}-1.20 \mu \mathrm{m})$ is roughly below 0.02 with the peak below 0.04 . The design realizes that the material can reflect nearly $99 \%$ sunlight $(0.40 \mu \mathrm{m}-1.20 \mu \mathrm{m})$ and let nearly $75 \%$ indoor thermal radiation $(8 \mu \mathrm{m}-13 \mu \mathrm{m})$ out. In a word, the cooling effect of this design is pretty well.
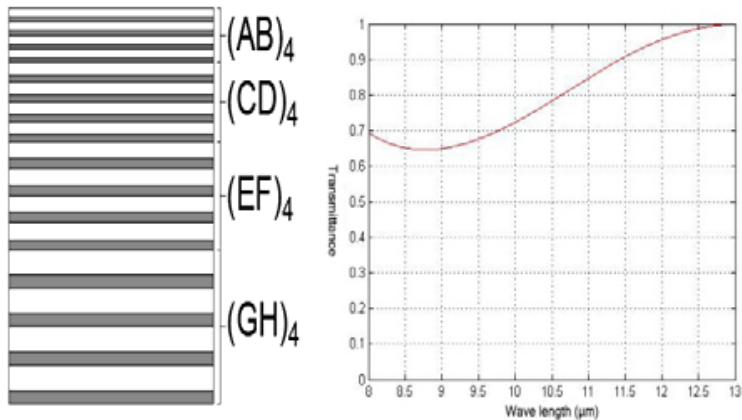

Figure 3. Structure of the designFigure5. Wave length $(8 \mu \mathrm{m}-13 \mu \mathrm{m})$-transmittance relationship

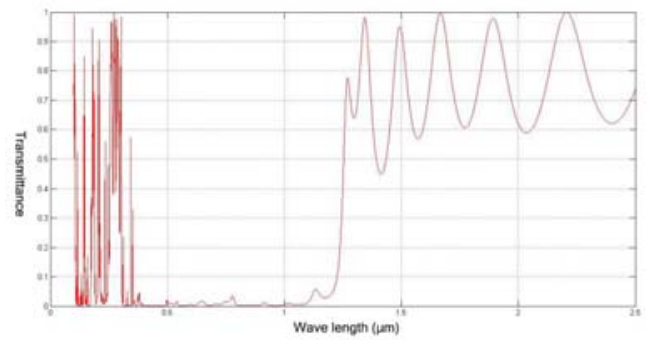

Figure 4. Wave length $(0.2 \mu \mathrm{m}-2.5 \mu \mathrm{m})$-transmittance relationship

\section{B. Design for windows}

With the same reason, again we choose $\mathrm{SiO}_{2}$ as the first layer (transmittance: 1.45) and $\mathrm{TiO}_{2}$ (transmittance: $2.65)$ as the second layer. The structure is, as is shown in figure 6. Also, layer A,C,E,G correspond to $\mathrm{SiO}_{2}$ while layer $\mathrm{B}, \mathrm{D}, \mathrm{F}, \mathrm{H}$ correspond to $\mathrm{TiO}_{2}$. Here, natural lighting ought to be carefully considered. To decrease specific period of infrared light $(0.76 \mu \mathrm{m}-1.20 \mu \mathrm{m})$ as much as possible but ensure high transmittance of visible light $(0.40 \mu \mathrm{m}-0.76 \mu \mathrm{m})$, the center positions of photonic band gap of layer $\mathrm{A}, \mathrm{B}, \mathrm{C}, \mathrm{D}, \mathrm{E}, \mathrm{F}$ are set to $0.85 \mu \mathrm{m}, 0.85 \mu \mathrm{m}$, $0.90 \mu \mathrm{m}, 0.90 \mu \mathrm{m}, 1.00 \mu \mathrm{m}, 1.00 \mu \mathrm{m}$. To widen the range of photonic band gap, the center positions of photonic band gap of layer $\mathrm{G}, \mathrm{H}$ are set to $1.10 \mu \mathrm{m}, 1.20 \mu \mathrm{m}$. Calculated by formulas above, The thickness of layer A,B,C,D,E,F,G,H are $147 \mathrm{~nm}, 80 \mathrm{~nm}, 155 \mathrm{~nm}, 85 \mathrm{~nm}, 172 \mathrm{~nm}, 94 \mathrm{~nm}, 190 \mathrm{~nm}$, $113 \mathrm{~nm}$. The results are shown in figure 7 and figure 8 . We can find out that transmittance of specific period of infrared light $(0.76 \mu \mathrm{m}-1.20 \mu \mathrm{m})$ is roughly below 0.01 with the peak below 0.04 and transmittance of visible light $(0.40 \mu \mathrm{m}-0.76 \mu \mathrm{m})$ is approximately above 0.65 except for some period of red and purple light. The design realizes reflecting nearly $99 \%$ thermal radiation in specific period of infrared light $(0.76 \mu \mathrm{m}-1.20 \mu \mathrm{m})$ but letting more than $60 \%$ visible light $(0.40 \mu \mathrm{m}-0.76 \mu \mathrm{m})$ in and about $85 \%$ indoor thermal radiation $(8 \mu \mathrm{m}-13 \mu \mathrm{m})$ out. In a word, this design relatively ideally meets the requirement of fairish natural lighting and good cooling effect. 


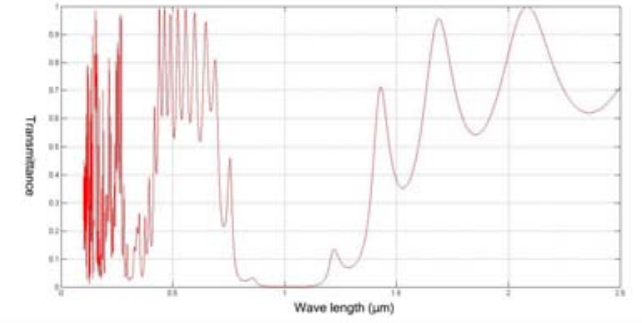

Figure7. Wave length $(0.2 \mu \mathrm{m}-2.5 \mu \mathrm{m})$-transmittance relationship
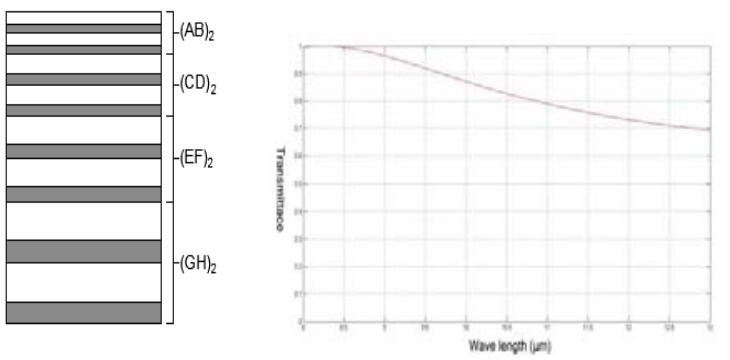

Figure6. Structure of the designFigure8. Wave length $(8 \mu \mathrm{m}-13 \mu \mathrm{m})$-transmittance relationship

\section{Limitations on application}

In our opinions, limitations on application for this material are as follows:

1. Difficulties in large-scale production: Nowadays, production of one-dimensional photonic crystal is merely for high-precision optical devices. Hence, easier structure, cheaper layer material and more efficient manufacturing technique ought to be found out.

2. Problems after application: Firstly, the thin film will help buildings lose heat in winter unless taken off. But photonic crystal is a kind of fragile material, which is easy to be broken when taken off or transported. Next, if exposed to high temperature in summer for long, the volume will expand and the shape may transform, changing optical properties of the material. What's more, the extremely high reflectivity of this material is bound to deteriorate light pollution in summer.

\section{Ideas about further researches}

Our ideas about further researches are as follows.

\section{1) Ideas about photonic material for cooling}

1. Add other materials to improve usability: Add layers with other material to make the whole film resistance to hit, high temperature, abrasion, strong rainfall and acid in rain.

2. Widen photonic band gap: it is contradictory that we need a wide enough photonic band gap with an easy enough structure and few enough loops. Therefore, relative solutions remain to be put forward.

2) Ideas about photonic material for heating

Referring to designs for cooling, we let visible light $(0.40 \mu \mathrm{m}-0.76 \mu \mathrm{m})$ and specific period of infrared light $(0.76 \mu \mathrm{m}-1.20 \mu \mathrm{m})$ in and keep indoor thermal radiation $(8 \mu \mathrm{m}-13 \mu \mathrm{m})$ not out by setting suitable position of the photonic band gap. However, things become more complex now. Owing to the character that odd times $(1,3$, $5 \ldots)$ of fundamental frequency $\left(\omega_{0}\right)$ are also in photonic band gap and wave length $(\lambda)$ is in reciprocal relationship with frequency $(\omega)$, there are band gaps in $1 / 3 \lambda_{0}, 1 / 5 \lambda_{0} \ldots$ Some of the period above $(0.40 \mu \mathrm{m}-1.20 \mu \mathrm{m})$ is bound to be included in the band gap if we follow the train of thought above. Hence, whether heating can be realized needs further calculations.

3) 5.3.3Ideas about heating in winter and cooling in summer

If photonic material for heating is proven to be true, we can find materials which in different temperature properly change thickness or existing form (refractive index will change along with) with the effect of heating in winter and cooling in summer. Anyway, this isthe ideal photonic material for buildings in energy saving.

\section{REFERENCES}

[1] Aaswath P. Raman1, Marc Abou Anoma2, Linxiao Zhu3, Eden Rephaeli1 \& Shanhui Fan1.Passive radiative cooling below ambient temperature under direct sunlight[J].Nature,2014(11):540-550.

[2] Guo Shuohong.Electrodynamics [M].Beijing:Higher Education Press, 2011:135-140. (in Chinese)

[3] Ma Xiying. The theory and application of photonic crystal[M].Beijing: Science Press, 2010:9-10,35-38. (in Chinese)

[4] Meng Hua, Gu Peifu. Passive cooling and radiative cooling[D]. Shanghai: Tongji University, 2003. (in Chinese) 